\title{
Multi-objective whale optimization based minimization of loss, maximization of voltage stability considering cost of DG for optimal sizing and placement of DG
}

\author{
J. P. Sridhar ${ }^{1}$, R. Prakash ${ }^{2}$ \\ ${ }^{1}$ Departement of Electrical and Electronics Engineering, SJB Intstitute of Technology, India \\ ${ }^{2}$ Departement of Electrical and Electronics Engineering, Acharya Institute of Technology, VTU Belagavi, India
}

\begin{tabular}{l} 
Article Info \\
\hline Article history: \\
Received Jul 16, 2018 \\
Revised Sep 20, 2018 \\
Accepted Oct 14, 2018 \\
\hline
\end{tabular}

Keywords:

Distributed generation

Multi-objective

Optimal placement

Photo-voltaic

Whale optimization

\begin{abstract}
Huge need in electricity causes placement of Distribution Generation (DG)s like Photovoltaics (PV) systems in distribution side for enhancing the loadability by improving the voltage stability and minimization of loss with minimum cost. Many optimal placements of DG have done in focus of minimum loss and improving voltage profile. This Whale optimization is a new optimization technique framed with mathematics of spiral bubble-net feeding behavior of humpback whales for solving a power system multiobjective problem considering cost of the power tariff and DG. Here main objectives are minimizing loss and cost with maximization of voltage stability index. IEEE 69 power system data is used for solution of the proposed method.
\end{abstract}

Copyright $@ 2019$ Institute of Advanced Engineering and Science. All rights reserved.

Corresponding Author:

J. P. Sridhar,

Departement of Electrical and Electronics Engineering,

SJB Institute of Technology,

Uttharalli, main road, kengeri, Bangalore 560060, Karnataka, India.

Email: srihdk@gmail.com

\section{INTRODUCTION}

The need of distribution side planning is becoming important due to the need of electricity is increased. The optimal placement of DG and sizing is done by many researches to improve voltage profile and losses [1]-[4]. Various algorithms like Particle swarm optimization (PSO), bat algorithm and cuckoo search algorithms are used in [1]-[4] for minimization of loss and improving the voltage. Multi-objective optimization is also done by many researches like improving voltage profile and minimization of losses [5], [6]. But cost based analysis is not carried out more.

In [6] cost of the DG and cost of the tariff is considered for the solution of optimal placement. In this paper whale optimization of multi-objective solution in optimal placement of PV based DG is implemented to minimize loss and cost with maximization of VSI.

\section{SOLAR MODELED AS DG}

The PV module generated power depends upon solar irradiance, ambient temperature and module characteristics. The PV array output power at solar irradiance s can be calculated using [3].

$$
\begin{aligned}
& P^{P V}=N \cdot F F \cdot V_{y} \cdot I_{y} \\
& V_{y}=V_{o c}-K_{v} \cdot T_{c y}
\end{aligned}
$$




$$
\begin{aligned}
& I_{y}=s\left[I_{s c}+K_{i}\left(T_{c y}-25\right)\right] \\
& F F=V_{M P P T} \cdot \frac{I_{M P P T}}{V_{o c} I_{S c}} \\
& T_{c y}=T_{A}+s\left(\frac{N_{O T}-20}{0.8}\right)
\end{aligned}
$$

Where,

$T_{c y} \& T_{A}$ - the $\mathrm{PV}$ module temperature and ambient temperature $\left(\right.$ in $^{\circ} \mathrm{C}$ )

$N_{O T} \quad$ - module nominal operating temperature $\left(\right.$ in $\left.{ }^{\circ} \mathrm{C}\right)$

$I_{s c} \quad$ - short circuit current (A)

$V_{o c} \quad$ - open circuit voltage (V)

$K_{v} \quad$ - temperature coefficient of voltage

$K_{i} \quad$ - temperature coefficient of current

$F F \quad$ - fill factor

$N \quad$ - the total number of PV modules

$I_{M P P T} \quad$ - maximum power point for current (A)

$V_{M P P T}$ - maximum power point for voltage (V)

DGs are of various types. These are classified mainly on the basis of fuel used, renewable energy and non-renewable energy, capacity of generation, electrical output etc. Based on real and reactive power delivery capacity, DGs are categorized into four major types.

Type1: PVs capable of generating only active power. These are asynchronous based DG technology.

Type2: PVs capable of generate both real and reactive power.

\section{MULTI-OBJECTIVE PROBLEM FORMULATION}

The objective functions (OF) are to minimize real power Loss, maximize voltage stability index and minimize cost of loss with cost of DGs in radial distribution system, while taking care of voltage limit of the system. Weight method is used in this paper to convert multi-objective functions (MOF) into a single objective function. The objective function is represented mathematically as:

$$
\min F=W 1 \cdot F 1+W 2 \cdot F 2+W 3 \cdot F 3
$$

Here, F1 - Real power loss

F2 - Voltage stability index

F3 - Combined cost of power loss (CPD) and DG cost (CPDG)

Where, $\mathrm{W} 1, \mathrm{~W} 2$ and $\mathrm{W} 3$ are weight factors here $\mathrm{W} 1+\mathrm{W} 2+\mathrm{W} 3=1$

Power Losses: The total real power losses at all nodes cause by circulating current in the network by substation and DGs are calculated. This objective function is formulated as:

$$
F 1=\frac{P_{\text {Loss } D G}}{P_{\text {loss }}}
$$

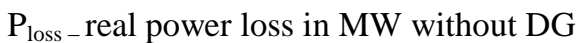

$\mathrm{P}_{\text {loss } \mathrm{DG}}$ - Real power in loss in MW with DG placed

Voltage Stability Index (VSI): Distribution system is generally radial in structure. The buses which are far away from the substation are subject to more voltage drop and hence, sensitive to voltage collapse. So, to identify the buses which are most sensitive to voltage collapse, VSI is used in [4].

$$
V S I(r)=\left|V_{s}\right|-4\left[P_{r}(r) R_{r}+Q_{r}(r) X_{r}\right]\left|V_{s}\right|^{2}-4\left[P_{r}(r) R_{r}-Q_{r}(r) X_{r}\right]^{2}
$$

VSI is the voltage of sending end node where as $\mathrm{Vr}, \mathrm{Pr}, \mathrm{Qr}, \mathrm{Rr}$ and $\mathrm{Xr}$ are receiving end node voltage, reactive power, resistance and impedance.

$$
F 2=\frac{1}{\min (V S I(r))}
$$

Here $\mathrm{r}=2,3$. .total number of bus 
Cost function: Cost is based on the lost power in MW as well as the DG generated power, the cost of DG (CPDG) is taken as 46 US \$/MWh and the power loss Cost (CPD) is taken as 44.5 \$/MWh.

$$
\begin{aligned}
& \text { Total Cost }=\frac{\left\{C P D G \sum_{i=1}^{n} P_{d g, i}+C P D . P_{\text {Loss } D G}\right\}}{C P D . P_{\text {Loss }}} \\
& \text { In optimization function } F 3=\frac{1}{\text { Total Cost }}
\end{aligned}
$$

Here $\mathrm{P}_{\mathrm{dg}, \mathrm{i}}-$ is the PV connected at $\mathrm{i}^{\text {th }}$ bus

This objective is constrained with Voltage limit $(0.95<\mathrm{V}<1.05)$, line limit and power flow limits.

\section{WHALE OPTIMIZATION METHOD [7]}

The most interesting thing about the humpback whales is their special hunting method. This foraging behavior is called bubble-net feeding method [7]. Humpback whales prefer to hunt school of krill or small fishes close to the surface. It has been observed that this foraging is done by creating distinctive bubbles along a circle or '9'-shaped path. Before 2011, this behavior was only investigated based on the observation from surface. However, Gold-bogen investigated this behavior utilizing tag sensors. They captured 300 tag-derived bubble-net feeding events of 9 individual humpback whales. They found two maneuvers associated with bubble and named them 'upward-spirals' and 'double-loops'. In the former maneuver, humpback whales dive around $12 \mathrm{~m}$ down and then start to create bubble in a spiral shape around the prey and swim up toward the surface. The later maneuver includes three different stages: coral loop, lobtail, and capture loop. It is worth mentioning here that bubble-net feeding is a unique behavior that can only be observed in humpback whales. In this work the spiral bubble-net feeding maneuver is mathematically modeled in order to perform optimization of DG place and size. The procedure is given below,

Step 1: Initialize the whale's population $X_{i j}(i=1,2, \ldots, n) j=$ number of search variables (location and size of DG)

Step 2: Calculate the fitness of each search agent

$\mathrm{X}^{*}=$ the best search agent

Step 3: check the maximum number of iterations reached for each search agent. Update a, A, C, 1, and p. (here, $\mathrm{A} \& \mathrm{C}$ - coefficient vector, a- linearly decreased from 2 to 0,1 is the random number between $[-1,1], p$ is random number between $[0,1])$.

Step 4: if $\mathrm{p}<0.5$ and $|\mathrm{A}|<1$ then Update the position of the current search agent by the Equations (12), (13)

$$
\begin{aligned}
& D=|C \cdot X(t)-X(t)| \\
& X(t+1)=X(t)-A \cdot D
\end{aligned}
$$

Here $\mathrm{t}$ is iteration count.

else if $|A|>=1$ Select a random search agent $\left(\mathrm{X}_{\text {rand }}\right)$. Update the position of the current search agent by the Equation (14).

$$
\mathrm{X}(\mathrm{t}+1)=\mathrm{X}_{\text {rand }}-\mathrm{A} \cdot \mathrm{D}
$$

Step 5: if $p>=0.5$ Update the position of the current search by the Equation (15)

$$
X(t+1)=D^{\prime} \cdot e^{b l} \cdot \cos (2 \cdot \pi l)+X^{*}(t)
$$

Step 6: Check if any search agent goes beyond the search space and amend it Calculates the fitness of each search agent. Update $X^{*}$ if there is a better solution increment iteration count $t=t+1$ and go to Step 3 .

Step 7: Display result $X^{*}$

\section{RESULTS AND DISCUSSION}

The proposed method is verified on a 69 bus radial distribution system. The power of all network buses are assumed to be delivered by the substation placed at node 1 . The total real power loads and reactive power loads on the 69 radial distribution system are 3.80 MW and 2.69 Mvar respectively. The objective functions values before installation of DG, which include the total power losses and VSI values, are 0.2250 MW and 0.6883 respectively. In order for directly obtained the optimal siting and sizing of DG in the 
distribution system with the target of minimizing the total real power losses and improve voltage stability while maintain the acceptable voltage limit, the whale optimization algorithm is used, which is a selfdeveloping code, built using Matlab script functions.

\section{Cases under study}

In this paper Type1 and Type 2 DGs are considered for study. Hence, there are two cases:

Case I: Optimal allocation of Type1 DGs i.e. DG capable of generating only active power. For single DG

Case II: Optimal allocation of Type1 DGs i.e. DG capable of generating only active power. For two DG

Case III: Optimal allocation of Type1 DGs i.e. DG capable of generating only active power. For three DG

Case IV: Optimal allocation of Type2 DGs i.e. DG capable of generating both active and reactive power. These DGs are considered to have constant power factor of 0.85 (lagging) with one DG

Case V: Optimal allocation of Type2 DGs i.e. DG capable of generating both active and reactive power. These DGs are considered to have constant power factor of 0.85 (lagging) with two DG

Case VI: Optimal allocation of Type2 DGs i.e. DG capable of generating both active and reactive power. These DGs are considered to have constant power factor of 0.85 (lagging) with three DG

Table 1 shows the place and size of DG in all the six cases with two types of DGs. Here the DG are considered with PV based generators. The cost of the DG is considered as $46 \$ / \mathrm{MWh}$ and cost of loss is considered as 44.5\$/MWh [6].

Table 1. Obtained Results

\begin{tabular}{|c|c|c|c|c|c|c|c|c|c|c|c|}
\hline \multirow[t]{2}{*}{ Type } & \multirow[t]{2}{*}{ Case } & \multicolumn{3}{|c|}{$\begin{array}{l}\text { Optimal } \\
\text { place }\end{array}$} & \multicolumn{3}{|c|}{ Optimal size in MW } & \multirow{2}{*}{$\begin{array}{c}\text { Loss in } \\
\text { MW }\end{array}$} & \multirow[t]{2}{*}{ VPI } & \multirow[t]{2}{*}{ Obj } & \multirow{2}{*}{$\begin{array}{c}\text { Cost } \\
\text { in } \$ / \mathrm{MWh}\end{array}$} \\
\hline & & DG1 & DG2 & DG3 & DG1 & DG2 & DG3 & & & & \\
\hline \multirow[t]{3}{*}{1} & Case 1 & 61 & - & - & 2.2 & - & - & 0.0868 & 0.886 & 0.492 & 105.0626 \\
\hline & Case 2 & 12 & 61 & - & 1.2 & 2 & - & 0.0785 & 0.957 & 0.444 & 58.69325 \\
\hline & Case 3 & 12 & 61 & 68 & 5 & 1.9 & 1 & 0.0784 & 0.942 & 0.433 & 320.8888 \\
\hline \multirow[t]{3}{*}{2} & Case 4 & 61 & - & - & 2.1 & - & - & 0.0255 & 0.9 & 0.408 & 97.73475 \\
\hline & Case 5 & 13 & 61 & - & 0.8 & 1.9 & - & 0.0104 & 0.9772 & 0.353 & 124.6628 \\
\hline & Case 6 & 2 & 17 & 61 & 4.9 & 0.6 & 1.8 & 0.0082 & 0.9773 & 0.329 & 336.1649 \\
\hline
\end{tabular}

The cost wise best one is Type 2 - case 4. In sort of improvement in VSI then case 2. In case of power loss it is case 6 . So the choice can be made with cost, loss and VSI parameter to implement in real time system. And from the cost analysis it can be seen that based on cost analysis there is a more than $90 \%$ need of the cost for placement of DG in all the cases. This cost based analysis with DG placement is not done in any literature. Convergence graph for TYPE-1 DG shown in Figure 1. Convergence graph for TYPE-2 DG shown in Figure 2. Improvement of results shown in Figure 3.

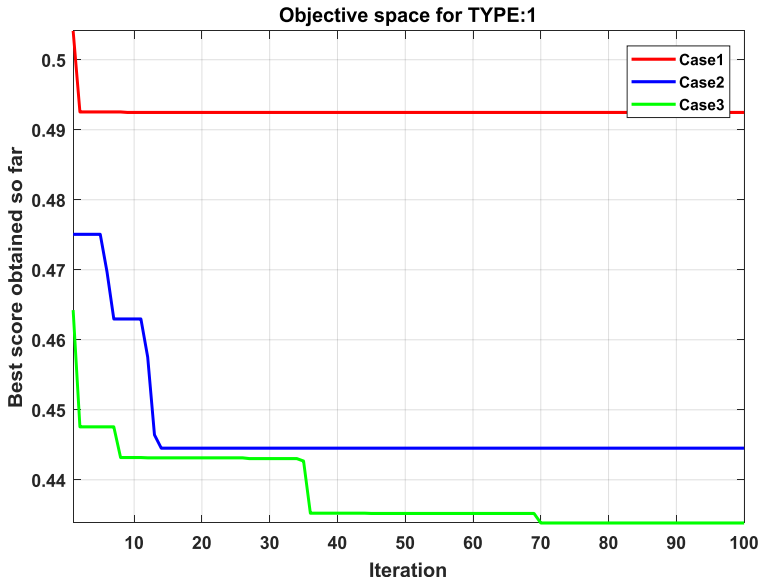

Figure 1. Convergence graph for TYPE-1 DG

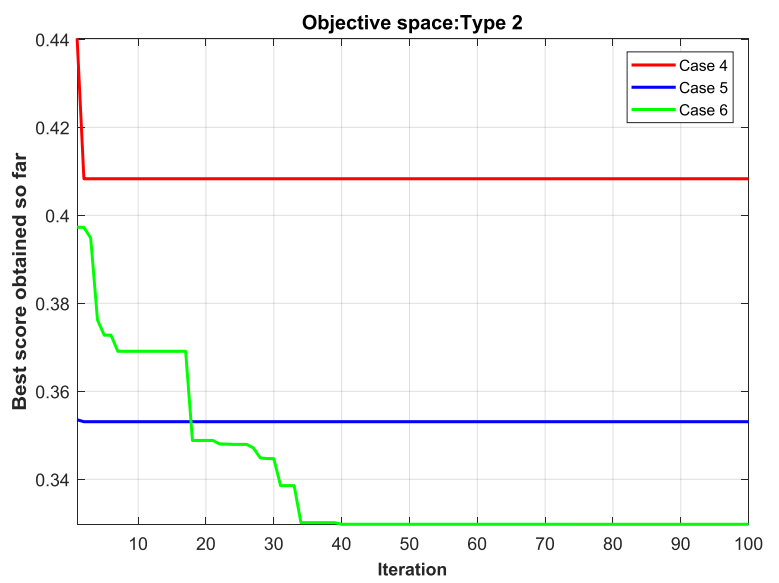

Figure 2. Convergence graph for TYPE-2 DG 


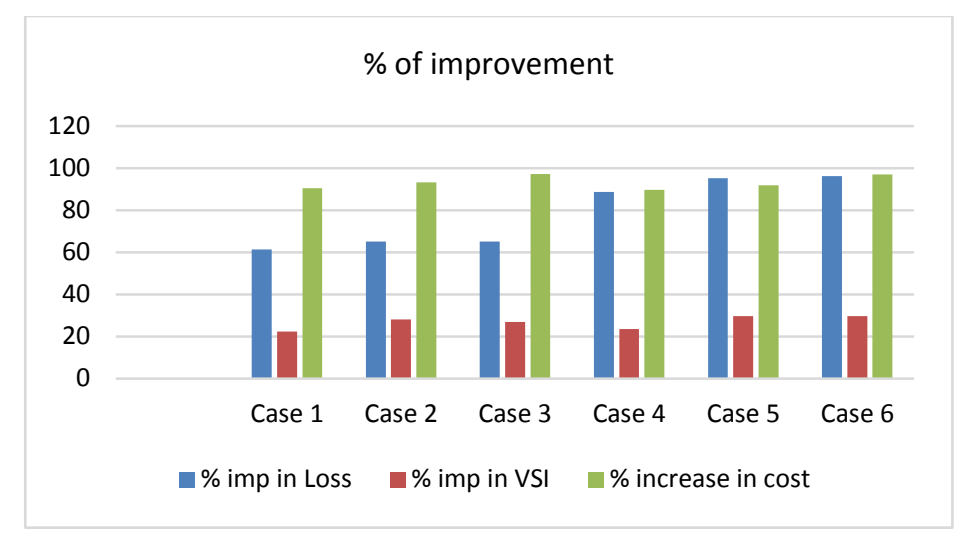

Figure 3. Improvement of results

\section{CONCLUSION}

The whale optimization based multi-objective solution of optimal DG placement is done with IEEE 69 bus system with standard cost and data. In multi-objective minimization of cost and real power loss with maximization of VSI is considered. The results show that there is a need for $90 \%$ more cost to place the DG in the system. And here PV based DG model is used for placement and sizing problem. The solution shows verity of choices for optimal placement and sizing of DG in real system.

\section{REFERENCES}

[1] W. S. Tan, M. Y. Hassan, M. S. Majid, and H. A. Rahman, "Allocation and Sizing of DG Using Cuckoo Search Algorithm," IEEE International Conference on Power and Energy (PECon), 2-5 December 2012, Kota Kinabalu Sabah, Malaysia.

[2] Mukul Dixit, Prasanta Kundu and Hitesh R. Jariwala, "Optimal Placement of PV Array in Distribution System for Power Loss Minimization Considering Feeder Reconfiguration," IEEE 16th International Conference on Environment and Electrical Engineering (EEEIC), 2016.

[3] Suresh Kumar Sudabattula, Kowsalya M, "Optimal allocation of solar based distributed generators in distribution system using Bat algorithm," IEEE 16th International Conference on Environment and Electrical Engineering (EEEIC), 2016.

[4] Ram Prakash and B.C. Sujatha "Optimal Placement and Sizing of DG for Power Loss Minimization and VSI Improvement using Bat Algorithm," National Power Systems Conference (NPSC), 2016.

[5] Singh, R.K.; Goswami, S.K. "Multi-objective Optimization of Distributed Generation Planning Using Impact Indices and Trade-off Technique," Electr. Power Components Syst. 2011, 39, 1175-1190.

[6] Navdeep Kaur and Sanjay Kumar Jain, "Multi-Objective Optimization Approach for Placement of Multiple DGs for Voltage Sensitive Loads," energies.

[7] Seyedali Mirjalili, Andrew Lewis "The Whale Optimization Algorithm," Advances in Engineering Software, 2016.

\section{BIOGRAPHIES OF AUTHORS}
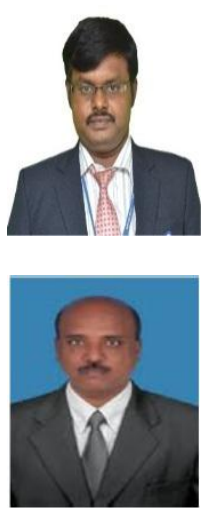

J.P. Sridhar obtained his B.E. and M. Tech degree from Visvesvaraya Technological University in 2007 and 2009 respectively. He is Pursuing Ph.D in the area of Power Quality Issues in Distributed Generation. Currently, he is working as Assistant professor in department of EEE, SJB Institute of Technology, Bengaluru, Karnataka.His areas of interest are Renewable Integration, Power Quality and Distributed Generation. E-mail: srihdk@gmail.com

Dr. R Prakash - Received B.E in Electrical and Electronics Engineering from Basaveshwara College of Engineering, Bagalkot, M.E in Power System Engineering from Walchand College of Engineering, Sangli And Ph.D. In Power System Engineering from Vtu, Belgaum. He is currently working as Professor and Head dept. of EEE, Acharya Institute of Technology, Bengaluru, Karnataka. His research interests include Power System, Renewable Energy, MicroGrids. E-mail: prakashrp1960@gmail.com 